\title{
The orphan nuclear receptor SHP inhibits apoptosis during the monocytic differentiation by inducing $\mathrm{p} 21$
}

KyeongJin $\mathrm{Kim}^{1}$, Yoon $\mathrm{Ha} \mathrm{Choi}^{2}$, Hyeong Hoe Kim ${ }^{3,4}$ and JaeHun Cheong ${ }^{1,4}$

${ }^{1}$ Department of Molecular Biology

Pusan National University

Busan 609-735, Korea

2Department of Life Science

Division of Molecular and Life Science

Pohang University of Science and Technology

Pohang 790-784, Korea

${ }^{3}$ Department of Experimental Medicine

College of Medicine, Pusan National University

Busan 601-721, Korea

${ }^{4}$ Corresponding authors: Tel, 82-51-510-2277;

Fax, 82-51-513-9258; E-mail, molecule85@ pusan.ac.kr (J.H. Cheong), Tel, 82-51-240-7414; E-mail, hhkim @ pusan.ac.kr (H.H. Kim)

DOI 10.3858/emm.2009.41.6.048

Accepted 22 January 2009

Abbreviation: SHP, small heterodimer partner

\begin{abstract}
Small heterodimer partner (SHP) is an atypical member of nuclear receptor superfamily that lacks a DNA-binding domain. In previous study, we showed that SHP, c-jun, p65 of NF-kB subunits, and p21WAF1 expression was increased during monocytic differentiaton with the exposure of human leukemia cells to a differentiation agent, PMA. In this study, c-Jun and p65 were shown to mediate the transcriptional activation of the SHP promoter. In addition, SHP induced the cell cycle regulatory protein levels and cooperatively increased an induction of p21WAF1 expression with p65. Furthermore, SHP protected differentiated cells from etoposide-induced cellular apoptosis through the induction and cytoplasmic sequestration of p21WAF1. Complex formation between SHP and p21WAF1 was demonstrated by means of coimmunoprecipitation. These results suggest that SHP prolongs a cellular survival of differentiating monocytes through the transcriptional regulation of target genes of cell survival and differentiation.
\end{abstract}

Keywords: apoptosis; cell differentiation; cyclin-de- pendent kinase inhibitor p21; monocytes; nuclear receptor subfamily 0 , group $B$, member 2

\section{Introduction}

The molecular mechanisms regulating cell differentiation involve a fine and complex balance of proteins and signal transduction pathways that modulate the progression through control of cell cycle and cell survival (Scott et al., 1994; Cory, 1995). Human macrophages are differentiated into noncycling cells arrested at the $\mathrm{G}_{1}$ checkpoint that derive from peripheral blood cycling human monocytes. Although little is known regarding the molecular mechanisms governing the monocyte differentiation to macrophage, promonocytic human cell lines, can be triggered to differentiate to human macrophages by defined stimuli (Oberg et al., 1993; Henkel et al., 1999). Agents such as phorbol esters (PMA) induce their exit from the cell cycle at $G 1$, leading to their differentiation, which is characterized by the appearance of macrophage-like features such as cell surface integrins, adherence to plastic, and the production of reactive oxygen intermediates (Freytag, 1988; Baeuerle and Henkel, 1994; Casini and Pelicci, 1999). U937, human leukemic lymphoma cell line with monoblastic characteristics, can be induced to differentiate towards morphologically mature macrophage-like cells after treatment with PMA (Larsson et al., 1988; Lubbert et al., 1991).

Treatment of myeloid leukemia cells with PMA is associated with changes in the expression of certain early- and late-response genes and level of modification of several transcription factors by signal pathway. PMA down-regulates c-myc transcripts in HL-60 cells and induces expression of the c-jun gene (Sherman et al., 1990; Szabo et al., 1991). Activation of Jun/AP-1 contributes to induction of $c$-jun transcription and monocytic differentiation (Angel et al., 1988; Szabo et al., 1991). The differentiated macrophages, in contrast to cycling monocyte, contain significant levels of NF- $\mathrm{kB}$ in the nuclei. The differentiation to macrophages triggered by plastic adherence or phorbol esters leads to a progressive degree of NF- $\mathrm{KB}$ nuclear translocation, a hallmark of differentiated macrophages. NF- $\mathrm{kB}$ plays a key role in cell differentiation by conferring cell survival that in the case of macrophages is 
mediated through p21 $1^{\text {WAF1/Cip1 }}$ (Pennington et al., 2001).

Small heterodimer partner (SHP) is an atypical orphan nuclear receptor that lacks a conventional DNA binding domain and consists only of putative ligand binding domain (Seol et al., 1996). SHP is expressed in a wide variety of tissues, with highest expression in heart, brain, liver, lung, and adrenal gland (Johansson et al., 2000). It has been reported that SHP represses the transcriptional activity of a number of nuclear receptors such as constitutive androstane receptor (CAR), esterogen receptor $(E R)$, thyroid hormone receptor (TR), Retinoid $X$ receptor (RXR), hepatocyte nuclear factor $4 \alpha$ (HNF $4 \alpha$ ), androgen receptor (AR), liver receptor homolog $1(\mathrm{LRH}-1)$, ER-related receptor- $\gamma$ (ERR $\gamma$ ), glucocorticoid receptor (GR), and liver $X$ receptor (LXR) (Seol et al., 1996; Lee et al., 2000; Johansson et al., 2000; Gobinet et al., 2001; Borgius et al., 2002; Brendel et al., 2002; Lee and Moore, 2002; Sanyal et al., 2002). Although SHP is well known as the repressor of various NRs, recently it is identified that SHP roles as a novel transcription coactivator of nuclear factor, NF-kB and appears to functions as a distinct regulatory component of the transcriptional activities of NF-KB in oxidized LDL-treated, resting macrophage cells (Kim et al., 2001b). It was reported that during the procedure of promonocyte cell differentiation of HL-60 leukemia cells toward the monocyte lineage by phorbol ester, mRNA and protein levels of SHP were increased in a time-dependent manner. It seems that SHP plays a fundamental role in the processes of monocytic differentiation (Choi et al., 2004). However, precise functions of SHP in monocytic differentiation have not been clearly elucidated. In the previous report, the role for SHP in the protection of cells against Nur77-mediated apoptosis has been proposed (Yeo et al., 2005). Anti-apoptosis function of SHP would be related with the resistance of phorbol ester-differentiated monocytes against apoptosis.

A number of transcription factors have been implicated in monocyte differentiation together with the transcriptional regulation of the downstream target gene expression, including $\mathrm{p} 21^{\text {WAF } 1}$ (hereafter referred to as p21) (Freytag, 1988; Nguyen et al., 1993; Scott et al., 1994; Nerlov and Graf, 1998; Wang et al., 1998; Kelly et al., 2000). p21 inhibits cell cycle progression by binding to $\mathrm{G}_{1}$ cyclin-CDK complexes through its $\mathrm{N}$-terminal domain. In addition, recent studies have shown that p21 promotes the association of Cdk4 with D-type cyclins, and targets Cdk4 and cyclin D1 to the nucleus (LaBaer et al., 1997). Thus, the cell cycle inhibitory activity of p21 is intimately correlated with its nuclear localization and this property appears to be responsible for the early stages of the differentiation program (Jiang et al., 1994; Steinman et al., 1994; Halevy et al., 1995; Andres and Walsh, 1996).

In this study, SHP-overexpressed cell represents resistance to apoptosis; moreover, p21 protein is significantly accumulated in the cytoplamic compartment as a basal level and induced rapidly by the apoptosis signal in the SHP-overexpressed cell line. Additionally, it was confirmed that SHP was induced from an early phase of monocytic differentiation prior to a dramatic increase of p21. Together, this study shows that SHP increased by signal of differentiation or apoptosis plays a role to protect monocytic cells from cell death through rapid and significant accummulation of p21 in the cytoplasmic compartment.

\section{Results}

\section{C-Jun and NF-кB p65 increase the transcriptional activation of the SHP promoter}

To investigate the influence on the basal level of cellular proteins related to monocytic differentiation, U937 cells were stimulated with PMA and assayed with immunoblotting. As shown as Figure $1 \mathrm{~A}, \mathrm{c}-J u n$ was induced and phosphorylated during the progression of differentiation. Furthermore, the level of $\mathrm{p} 65$ of NF-kB subunits, SHP, and p21 WAF1 were increased by the treatment of PMA. To gain insight that the differentiation signaling effects on the transcriptional activation of the SHP promoter, transient transfection assay was analyzed using the SHP promoter as a reporter construct with PMA. The result of Figure 1B shows that promoter activity of SHP is positively regulated by the treatment of PMA as a dose-dependent manner.

Cycling primary human monocytes have no $\mathrm{NF}-\kappa \mathrm{B}$ in their nuclei. However, their differentiation into macrophages triggered by PMA significantly leads to nuclear translocation of NF-KB. Its translocation into the nucleus by the PMA stimuli regulates various genes including monocytic differentiation and cell survival programs (Pennington et al., 2001). To investigate whether NF-kB regulates transcriptional level of SHP, p65 expression vector and SHP luciferase-based reporter were cotransfected. As a result, p65 increased the transactivation of the SHP promoter and p65 and c-Jun increased the expression level of SHP synergistically (Figure $1 \mathrm{C}$ ). It is supported by the report that SHP plays a role as a coactivator of p65 in macrophage cells (Kim et al., 2001b). Taken together, these results may indicate that the expression level of SHP is associated with transcriptional induction. 


\section{p21 induced by SHP in the late monocytic differentiation is sequestered in the part of the cytoplasm}

It was reported that NF- $\mathrm{BB}$ p65 directly interacts with SHP in vitro and in vivo and SHP plays a role as a coactivator of NF-KB (Kim et al., 2001b). To examine whether increased SHP by p65 contributes to induction of p21 transcriptional levels, SHP and p65 expression vector was cotransfected with p21 promoter-reporter vector. Single transcriptional activity of p65 on p21-promoter was not strong, in spite of the suggestion of the possibility that p65 directly regulates p21 gene expression (Pennington et al., 2001). However, promoter activity of $\mathrm{p} 21^{\mathrm{WAF} 1}$ was upregulated by $\mathrm{p} 65$ and
SHP synergistically (Figure 2A).

To obtain more information regarding increased expression, localization, and regulation of p65, SHP, and p21 in monocytic differentiation, U937 cells were stimulated with PMA for indicated times and nuclear and cytoplasmic fractions were obtained. As shown as Figure 2B, p65 was located in the cytoplasm in early differentiation, while in the late differentiation p65 translocated to the nucleus. Furthermore, the protein level of p21 was induced in the nucleus significantly at $24 \mathrm{~h}$ after treatment of PMA, and then decreased as time goes. In contrast, in the cytoplasm p21 was induced gradually after $24 \mathrm{~h}$ of PMA treatment. SHP was increased in the nucleus slightly from 12 to $24 \mathrm{~h}$.
A

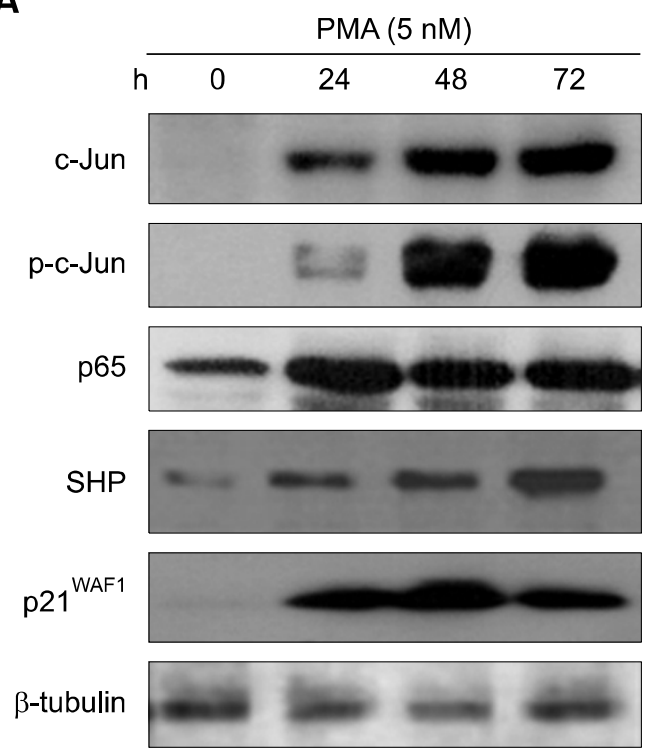

B

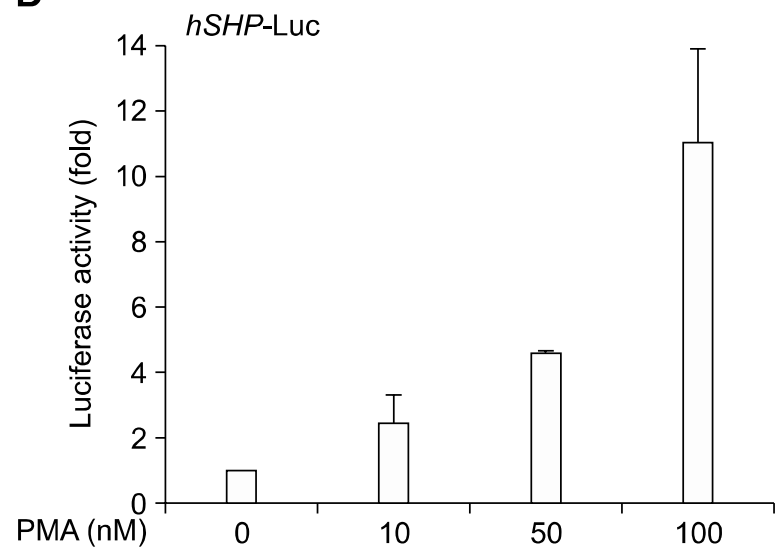

Figure 1. Increased expression of SHP, c-Jun, NF-אB, and p21 during U937 promonocytic cell differentiation. (A) U937 cells grown in suspension become adherent following exposure to $5 \mathrm{nM}$ PMA by $24 \mathrm{~h}$ with persistence of the phenotype for up to 3 days after the first appearance of the PMA treatments. The protein expressions of SHP, c-Jun, NF-kB p65, and p21 were examined with their cognate antibodies and phosphorylation of c-Jun was detected with anti-phospho-c-Jun antibody. Western blotting of $\beta$-tubulin was used as a loading control. (B) Human SHP promoter reporter plasmid was transfected. After $24 \mathrm{~h}$ following transfrection in absence or presence of several concentrations of PMA, as indicated, cells were harvested for luciferase assay. (C) Cells were transfected with indicated dose of p65 and c-Jun expression vector and human SHP promoter-luciferase plasmid together. Luciferase activity was measured and the values are expressed as the means \pm S.D. for at least three independent experiments.
C

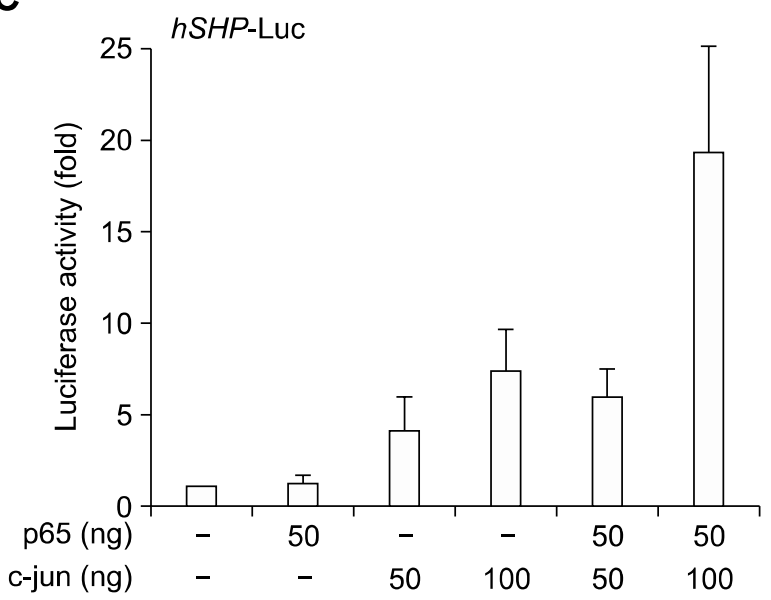


However, after $24 \mathrm{~h}$ of PMA treatment, SHP was significantly increased in the cytoplasm (Figure 2B). In order to analyze relationship between SHP and p21 in cytoplasmic localization, physical interaction between p21 and SHP was investigated by coimmunoprecipitation. As shown in Figure $2 \mathrm{C}$, p21 was detected in the immune complexes of SHP from SHP-overexpressed cells. Also, we verified that p21 interacted with SHP during PMAinduced monocytic differentiation of $U 937$ cells in endogenous cellular levels (Figure 2D).

\section{SHP-overexpressed cells are resistant to apoptosis induced by apoptogenic stimuli}

In the previous report, p21, originally identified as a cell cycle inhibitor, acts as an inhibitor of apoptosis in the cytoplasm (Asada et al., 1999). To identify the roles of the cytoplasmic translocalization of $p 21$ and SHP in cellular apoptosis, we established
A

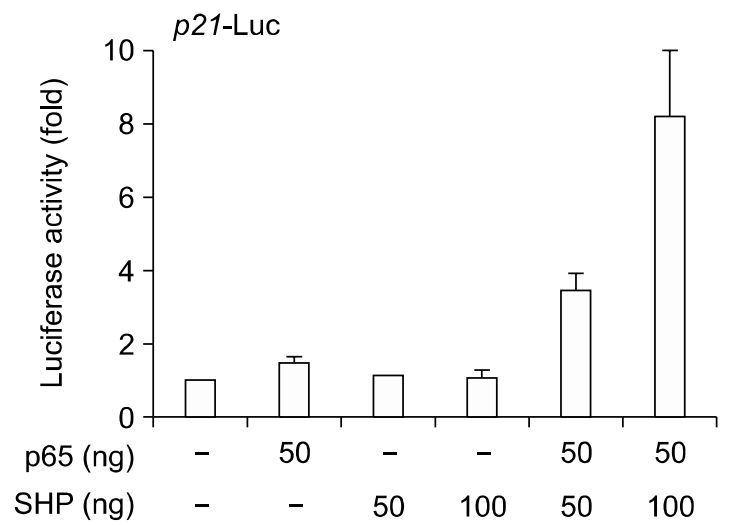

B

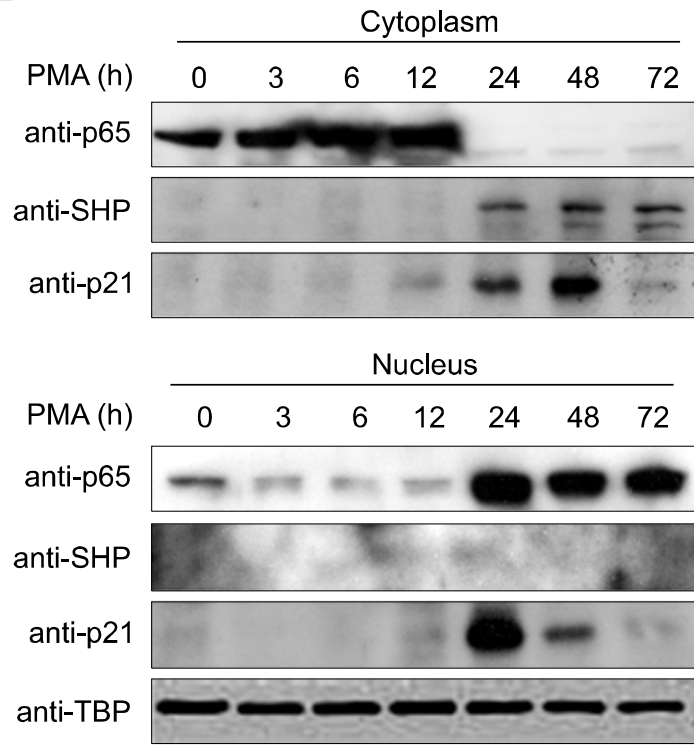

C

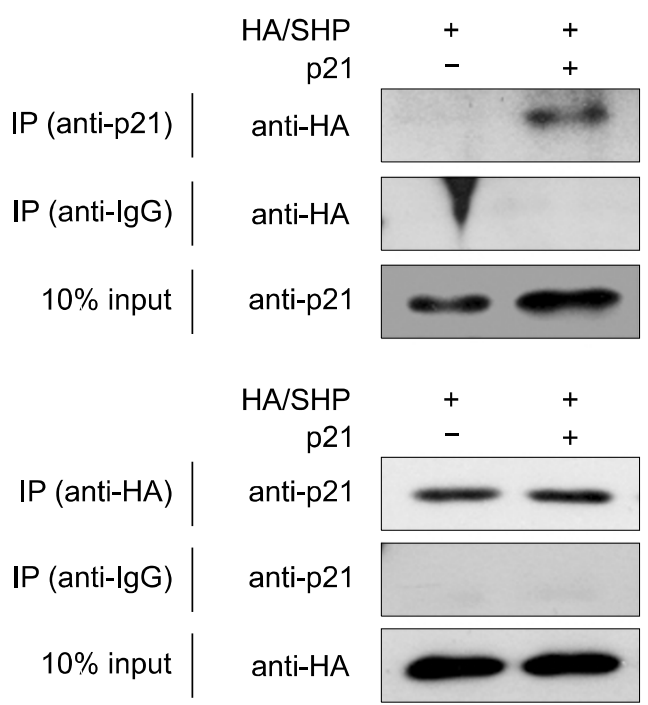

D

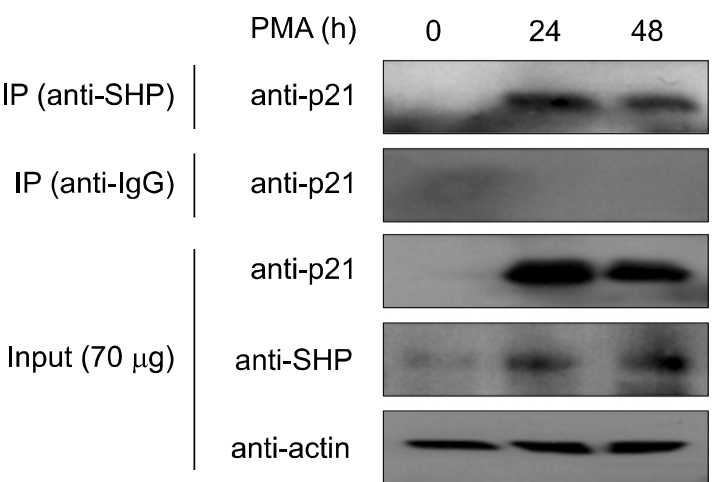

Figure 2. p21 induced by SHP in the late monocytic differentiation is sequestered in the part of the cytoplasm. (A) The p65 and SHP upregulate p21 promoter activity synergistically. The p21 promoter (100 ng) was cotransfected with the indicated amount of expression plasmid encoding SHP and p65 in the presence or absence of etoposide treatment. After $48 \mathrm{~h}$ of incubation, cell lysates were obtained and analyzed. Luciferase activity was normalized for transfection efficiency by corresponding $\beta$-gal activity. Data shown are the mean of three independent determinations. (B) The protein levels and cellular localizations of SHP and p21 are related with monocytic differentiation. U937 cells were treated with $2.5 \mathrm{nM}$ PMA and incubated for the indicated time and nuclear and cytoplasmic fractions were obtained. Each fraction was analyzed by 12\% SDS-PAGE and immunoblotted. (C) The interaction between SHP and p21 was identified by coimmunoprecipitation method. Total cell lysates were obtained and immunoprecipitated with anti-p21 or anti-HA antibody and then analyzed with anti-HA or anti-p21 antibody by Western blot analysis. (D) U937 cells were treated with PMA for the indicated times and were assessed to coimmunoprecipitation using antibodies specific for the SHP. IgG served as a negative control. The precipitates were analyzed via immunoblotting with antibodies specific for p21. 
SHP-overexpressing cells in HeLa cell lines. For this experiment, we used two kinds of stable cell clone isolated previously (S-1 and S-16). In SHPoverexpressing clones selected with G418, p21 protein level was significantly induced. To confirm the effect of increased p21 protein level on cell cycle and survival, the apoptosis susceptibility of mock and SHP overexpressing cells (S-1 cells) were tested by the method of DNA fragmentation assay and flow cytometry analysis. When mock transfectants were treated etoposide or $\mathrm{H}_{2} \mathrm{O}_{2}$, a large portion of cells underwent apoptosis; however, S-1 cells relatively showed resistance against apoptosis (Figure $3 A$ and $B$ ). This result strongly suggests that SHP is an important regulator of apoptotic cell death. Furthermore, in the condition of etoposide-mediated apoptosis, the protein level of SHP, but not mRNA levels of SHP, was remar- kably assessed (Figure 3C). As shown in Figure $3 \mathrm{D}, \mathrm{SHP}$ is conducive to rapid induction of p21 with treatment of etoposide. These results suggest that cellular sensitivity to apotosis in SHP-overexpressed cells is relevant to increased p2 $1^{\text {WAF1 }}$ expression.

\section{p21 induced by apoptotic stimuli is sequestered in the cytoplasmic localization}

In order to investigate the relationship with rapid induction of p21 and SHP in the presence of apoptotic stimuli, we tested the p21 promoter activity by SHP in the presence of etoposide. As shown in Figure 4A, the activity of reporter genes encoding p21 promoter was enhanced by SHP along with etoposide. Moreover, SHP was conducive to rapid induction of p21 proteins with treat-
A
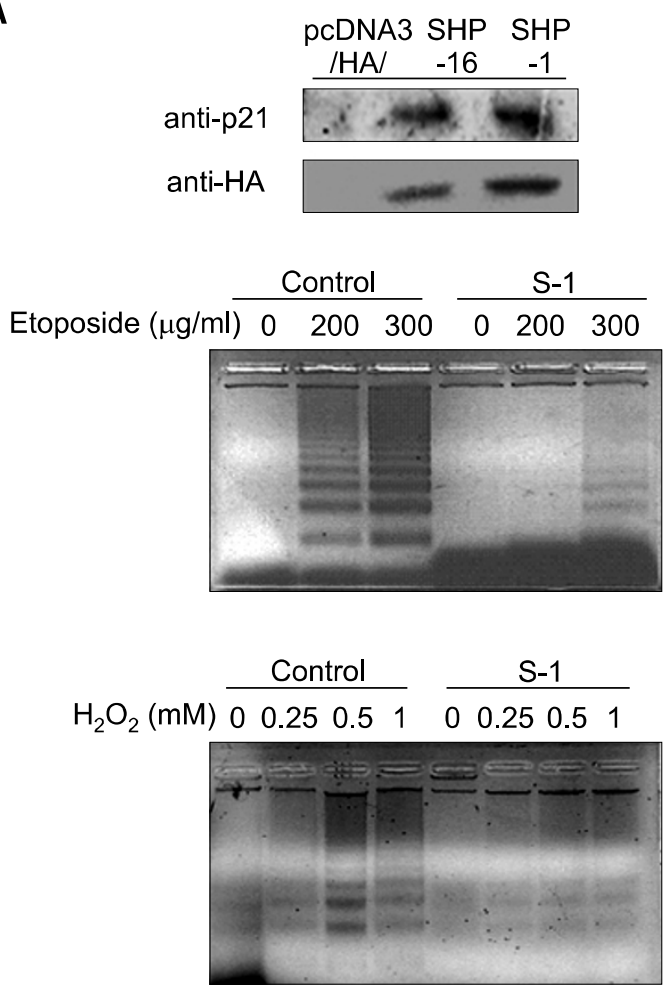

B

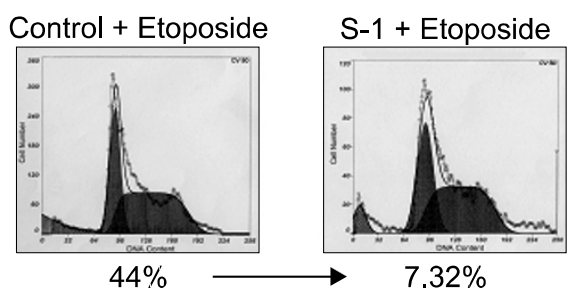

C

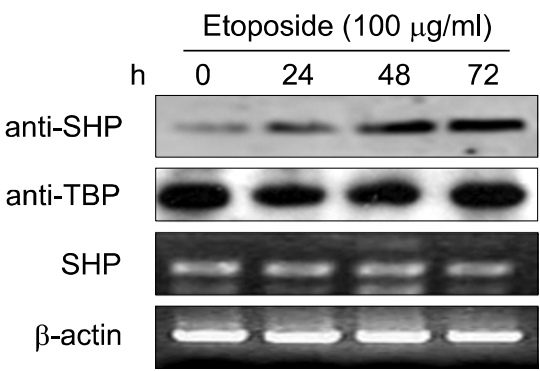

D

\begin{tabular}{|c|c|c|c|c|c|c|}
\hline \multirow[b]{2}{*}{ Etoposide $(\mathrm{h}$} & \multicolumn{3}{|c|}{ Control } & \multicolumn{3}{|c|}{ S-1 } \\
\hline & 0 & 16 & 38 & 0 & 16 & 38 \\
\hline anti-p21 & $=$ & - & 0 & - & & \\
\hline anti-Bax & & & & & & \\
\hline & & & & & & \\
\hline
\end{tabular}

Figure 3. SHP-overexpressed cells are resistant to apoptosis induced by apoptogenic stimuli. (A) SHP stably overexpressed clone was selected by the resistance against G418. Control and S-1 cells were incubated with or without etoposide or $\mathrm{H}_{2} \mathrm{O}_{2}$ and cells were harvested and subjected to extranuclear DNA extraction. Purified DNAs were electrophoresed in a $2 \%$ agarose gel and visualized by UV fluorescence after staining with ethidium bromide. (B) SHP inhibits apoptosis induced by treatments of etoposide. Cells were treated with etoposide for $16 \mathrm{~h}$ and fixed with $95 \%$ ethanol, washed twice with cold PBS, and treated RNase A. Cells were analyzed using flow cytometry for DNA content by PI staining. (C) U937 cells were treated with etoposide (100 $\mu \mathrm{g} / \mathrm{ml}$ ) for the indicated time intervals. After incubation, whole-cell lysates were assayed for SHP protein levels using western blotting. TBP expression is shown as a protein-loading control (upper panels). Total RNA from U937 cells were converted to ss-cDNAs by reverse transcriptase. These cDNAs were used as templates for PCR using SHP primers; $\beta$-actin primers were used as mRNA-loading control (lower panels). (D) Control and S-1 cells were treated with or without etoposide $(100 \mu \mathrm{g} / \mathrm{ml})$ in mild condition for 16 and $38 \mathrm{~h}$. At the end of incubation, whole-cell lysates were obtained and assayed for p21 and Bax expression by Western blot analysis. TBP expression is shown as a protein-loading control (S-1, SHP stable clone No. 1). 
ment of etoposide. Noteworthly, great part of increased p21 was detected in the cytoplasmic fraction; however, the protein level of p21 was increased in the nucleus either. In addition, basal protein level of p21 in the S-1 cells was much higher as compared with control cells (Figure 4B). To clarify the level and cellular localization of SHP and p21 related to monocytic differentiation and apoptosis, nuclear and cytoplasmic fractions were obtained. The presence of cytoplasmic p21 is related to the acquisition of the resistance against etoposide stimuli, the same expressional pattern of SHP and p21 gave the insight to further studies. When etoposide was induced in U937 with or without PMA, SHP and p21 were induced in the cytosolic compartment (Figure 4C). In order to determine whether SHP prevents the cell death as sequestering the cytoplasmic accumulation of 21 ,
A

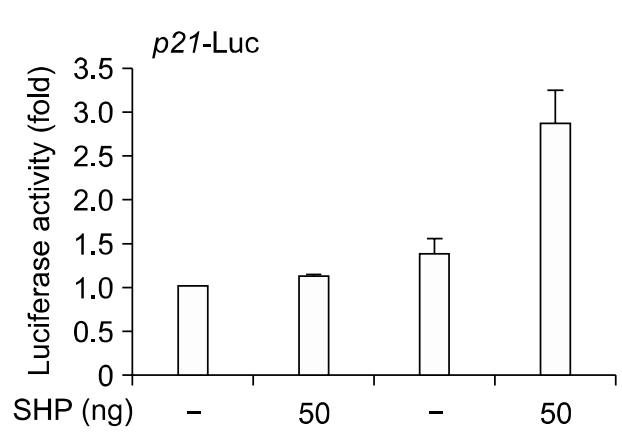

Etoposide $(\mu \mathrm{g} / \mathrm{ml}) \quad-\quad-\quad 50 \quad 50$

B

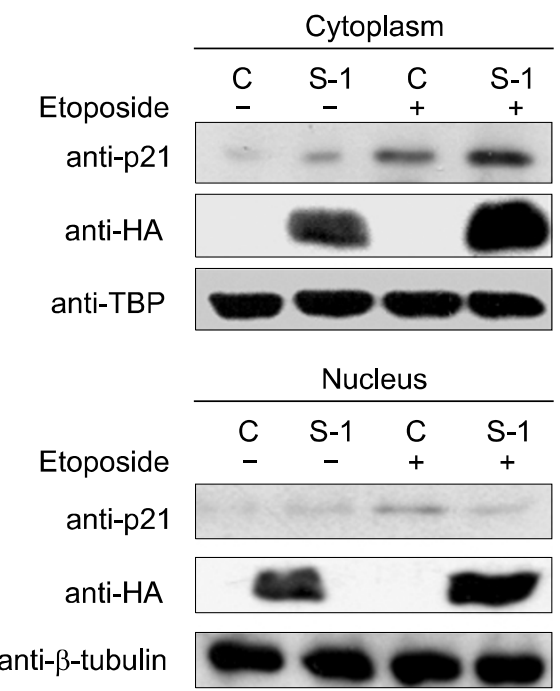

C

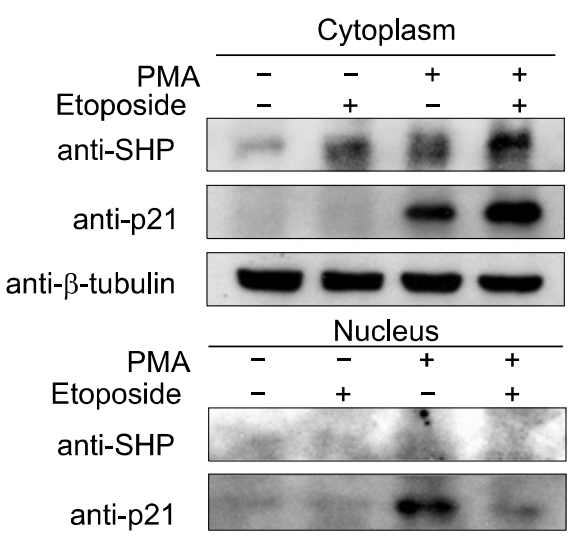

D

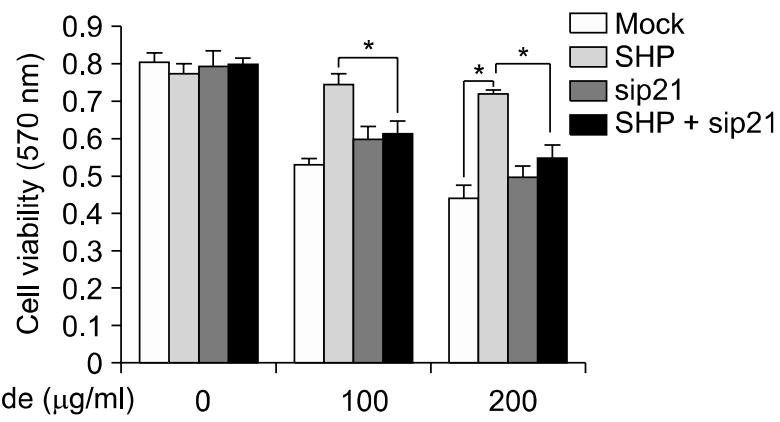

Etoposide $(\mu \mathrm{g} / \mathrm{ml}) \quad 0 \quad 100 \quad 200$

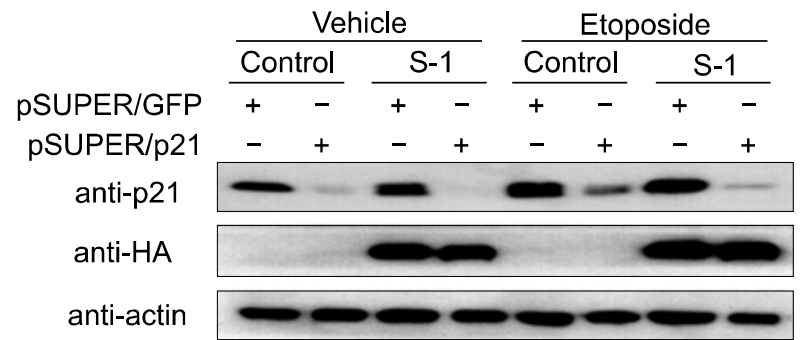

Figure 4. p21 induced by apoptotic stimuli is sequestered in the cytoplasmic localization. (A) SHP upregulated the promoter activity of p21. The reporter plasmid for human p21 promoter was transfected into HeLa cells. In $24 \mathrm{~h}$ after transfection in the absence or presence of etoposide for $12 \mathrm{~h}$, cells were harvested for luciferase assay. Luciferase activity was measured and the values are expressed as the means \pm S.D. for at least three independent experiments. (B) p21 is sequestered in the cytoplasmic compartment in SHP overexpressing cells. To examine the localization of p21, control and S-1 cells were treated with $100 \mu \mathrm{g} / \mathrm{ml}$ etoposide for $16 \mathrm{~h}$. After incubation, whole cell lysates were assayed by western blot analysis. The expression of $\beta$-tubulin is shown as a loading control for cytoplasmic protein. (C) U937 cells were treated with or without $2.5 \mathrm{nM}$ PMA for $48 \mathrm{~h}$ and then induced apoptosis with $50 \mu \mathrm{g} / \mathrm{ml}$ etoposide. Nuclear and cytoplasmic fractions were prepared and applied with Western blot analysis using antibodies against SHP and p21. The protein level of $\beta$-tubulin was measured for a loading control and a marker of cytoplasmic fraction. (D) Control and S-1 cells of equal numbers were transfected with siRNA for p21 to knockdown endogenous p21 expression. 3-(4,5-dimethylthiazol-2-yl)-2,5-diphenyltetrazolium bromide assay was performed to determine the effect of SHP and p21 on the cell viability exposed to the indicated doses of etoposide for $16 \mathrm{hr}$. The values are expressed as the means \pm S.D. ${ }^{*} P<0.05$ compared with the indicated control. The decreased protein expression of p21 with specific siRNA for p21 with the treatments of $100 \mu \mathrm{g} / \mathrm{ml}$ etoposide in control and S-1 cells was confirmed with Western blot analysis using anti-p21 antibody (lower panels). 
cells were transfected with or without SHP and siRNA for p21 in the absence or presence of etoposide. As shown in Figure 4D, treatment of etoposide significantly inhibited the viability of cells as measured by MTT assay. However, SHP-overexpressed cells did not prevent the apoptotic cell death in the treatment of etoposide when the increases of p21 were inhibited using siRNA for p21. Taken together, these results suggest that SHP may inhibit proapoptotic signals mediated by induction of $\mathrm{p} 21$.

\section{Discussion}

From the point of view of regulation, the process of cell differentiation could be conceptually composed of two steps: the commitment to differentiation and the subsequent expressions of genes that determine the phenotype of differentiated cells. The control of commitment is crucial for the timing of differentiation, whereas the control of subsequent gene expression is crucial for the determination of the particular differentiated phenotype. In this study, it was suggested that SHP takes a part in the process of monocytic differentiation and plays a critical role for viability specified to monocytic cells.

It was identified that SHP expression is abundant in murine macrophage cell line, RAW 264.7 (Kim et al., 2001b) and is upregulated during PMA-induced monocytic differentiation of HL-60 cells (Choi et al., 2004). By this report, it needed to identify the protein level of SHP in the stage of differentiation during promonocyte to monocyte. Concomitantly, the level of SHP protein was induced in the process of PMA-induced monocytic differentiation of U937 cells (Figure 1A). Other reports suggested that PMA-induced monocytic differentiation is deeply associated with the induction of c-Jun by activation of SAPK. Coexpression of C-Jun and SHP was also observed in heart, kidney, epididymus, prostate, and pancreas in addition to monocyte/macrophage. Based on this coexpression and its ability to transactivate the SHP promoter, it was confirmed that c-Jun is a potent regulator of SHP expression in this study (Figure 1C).

The present study provides a number of novel observations pertaining to the regulation and functional roles of NF-kB in monocytic cell differentiation. In the monocyte differentiation, NF- $\mathrm{KB}$ translocates to the part of nucleus and plays a critical role for the gene expression needed to differentiation. Also, it was reported that NF-kB mediates PTEN expression in TNF- $\alpha$-induced monocytic differentiation (Lee et al., 2007). It was identified that SHP acted as a novel transcription coactivator of NF-kB (Kim et al., 2001b). Interestingly, NF- $\kappa B$ and $C-J$ un together increased activity of SHP promoter synergistically (Figure 1C). It suggested the possibility that a certain signal pathway including activation of $N F-\kappa B$ and $c-J u n$ also targets on the regulation of SHP genes. We identified that SHP contributed on the transac-

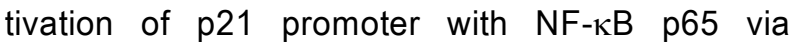
physical interaction between SHP and p65 (Data not shown). The protective effect of NF- $\mathrm{B}$ is, in part, mediated through $\mathrm{p} 21$, since this protein was found to be regulated in an NF-kB-dependent manner and to confer survival features during macrophage differentiation (Pennington et al., 2001). In this study, it was suggested that SHP and $\mathrm{NF}-\kappa \mathrm{B}$ may directly drive the transcription of $\mathrm{p} 21$.

During monocyte differentiation, the cell cycle inhibitory protein p21 translocates from the nucleus to the cytoplasm (Asada et al., 1999). Interestingly, whereas in the nucleus p21 functions as a cell cycle brake by binding to multi-cyclin/Cdk complexes and PCNA-DNA polymerase $\delta$ subunit (Sherr and Roberts, 1995), in the cytoplasm p21 can promote the assembly of cyclin D/Cdk4 complexes and their nuclear translocation (LaBaer et al., 1997). It was previously reported that in monocytes, p21 is expressed in the cytoplasm, where it acts as an inhibitor of apoptosis (Asada et al., 1999). Another novel function of cytoplasmic p21 associated with increased neurite outgrowth in developing neurons has been recently reported (Tanaka et al., 2002). Thus, cytoplasmic p21 exerts biological effects distinct from those of nuclear p21, and it is important to determine the regulatory mechanisms responsible for its cytoplasmic or nuclear expression. In this result, p21 and SHP was interacted in vivo (Figure $2 \mathrm{C}$ and $\mathrm{D}$ ), it is suggested that colocalization and interaction of p21 and SHP have the possibility to enhance cytoplasmic function of p21.

Recently, another important role for p21 in the protection of cells against apoptosis has been proposed. Accordingly, increased susceptibility to p53-mediated apoptosis in p21 deficient cells was observed in colorectal carcinomas and melanomas (Polyak et al., 1996; Gorospe et al., 1997). Inhibition of stress-mediated apoptosis in MCF-7 cells treated with prostaglandin A2 is also associated with p21 expression. In addition, p21 antisense therapy radiosensitizes human colon cancer cells exposed to the oxidative stress from apoptosis (Migliaccio et al., 1999; Kim et al., 2001a). Interestingly in differentiated human macrophages, p21 is predominantly located in the cytosol where it exerts an anti-apoptotic function by means of inhibiting the proapoptotic kinase Ask1 (Asada et al., 
1999). Interestingly, when SHP-overexpressed cells were resistant to apoptosis, the protein level of p21 was significantly induced (Figure $3 A$ and $B$ ). Particularly, several proteins related to the cell cycle were increased; however, there was no significant change of proliferation in the SHP- overexpressed cells (data not shown). Moreover, in the condition of evoked apoptosis, SHP was induced significantly in the level of native SHP protein as well as ectopic SHP protein (Figure 4B). It corresponds with the peculiar resistance of monocytic differentiated cells, therefore it is suggested that the increase of SHP in the monocytic differentiation contributes to the cell survival. As a reference of these reports, the cytoplamic localization of p21 in the SHP-overexpressed cells seems to have an important relationship with resistance to apoptosis (Figure 4C and D). In summary, this study demonstrates that SHP participates in the monocytic differentiation program and contributes to the acquisition of resistance to apoptosis by induction of $\mathrm{p} 21$.

\section{Methods}

\section{U937 cell culture and induction of differentiation}

U937 promyelocytic leukemia cells were cultured in RPMI 1640 medium supplemented with $10 \%$ heat-inactivated FBS, penicillin $100 \mathrm{U} / \mathrm{ml}$ and streptomycin $100 \mu \mathrm{g} / \mathrm{ml}$ (Gibco BRL). To induce monocyte differentiation, U937 cells were seeded at $2 \times 10^{5} / \mathrm{ml}$ and grown in the presence of $2.5 \mathrm{nM}$ PMA for up to 3 days. At the end of differentiation experiment, U937 cells were harvested and resuspended in an appropriate buffer for each experiment.

\section{Plasmid, reagent, and antibodies}

pSUPER/p21 siRNA400 was kindly donated by Dr. Michèle Sabbah (Fritah et al., 2005). pGL2B/hSHP-Luc (-2.2 kb) was kindly provided by Dr. Heung Sik Choi (Chonman National University, Korea). pCMX1/c-Jun, pcDNA3/p65, pGL3B/p21-Luc (-2300), or pcDNA3/HA/SHP was previously described, each other (Jang et al., 2001; Choi et al., 2004; Kim et al., 2007; Park et al., 2007).

The transfection reagent, PolyFect, was purchased from QIAGEN. All other reagents were purchased from Sigma. Antibodies against c-Jun (sc-1694), phosphor-c-Jun (sc-822), p65 (sc-372), SHP (sc-22040), $\beta$-tubulin (sc-5274), TBP (sc-273), p21 (sc-6246), or Bax (sc-493) were purchased from Santa Cruz Biotechnology, INC. and $\beta$-actin (A2066) or HA (1 867 423) antibodies were obtained from Sigma and Roche, each other.

\section{Transient and stable transfection}

Cells were maintained in DMEM supplemented with $10 \%$ heat-inactivated FBS and $1 \%$ antibiotics. The cells were seeded in 24-well plates with growth medium and cotrans- fected with $\beta$-gal vector, mammalian expression vectors for p65 of NF- $\mathrm{kB}$ subunits, c-jun, and reporter vectors. Total amount of expression vectors were kept constant by adding pcDNA3.1/HisC. Relative luciferase and $\beta$-galactosidase activities were determined. All the transfection results represent the mean of three independent experiments.

For establishment of the pcDNA3/HA/SHP expressing stable cell line, cells were transfected with $11 \mu \mathrm{g}$ of SHP expression plasmid (pcDNA3/HA/SHP) using calcium phosphate precipitation method. After $48 \mathrm{~h}$ from transfection, cells were cultured in the presence of $400 \mu \mathrm{g} / \mathrm{ml}$ G 418 .

\section{Coimmunoprecipitation}

Nuclear and cytosolic extract were prepared by a modification of the method of Dignam et al. (1983). For nuclear extract preparation, cells were washed twice and collected. Cells were lysed in buffer A containing $10 \mathrm{mM}$ HEPES, pH 7.9, $1.5 \mathrm{mM} \mathrm{MgCl}_{2}, 10 \mathrm{mM} \mathrm{KCl}, 0.5 \mathrm{mM}$ DTT, $0.2 \mathrm{mM}$ PMSF, 10\% Nonidet P-40 (NP-40). The nuclei were collected by centrifuge and lysed in $100 \mu \mathrm{l}$ of buffer B (20 mM HEPES, pH 7.9, $1.5 \mathrm{mM} \mathrm{MgCl}_{2}, 0.5 \mathrm{mM}$ DTT, 0.2 mM PMSF, 25\% Glycerol, $420 \mathrm{mM} \mathrm{NaCl}, 0.2 \mathrm{mM}$ EDTA). Immune complexes were immunopreipitated from clarified cell lysates with protein G-sepharose bead (Invitrogen) preincubated with antibody to p21 WAF1 (Santa Cruz Biotechnology, INC) and HA (Roche). The beads were washed extensively with buffer $A$, boiled in the loading buffer, separated by SDS-PAGE, and subjected to Western blot analysis.

\section{DNA fragmentation assay}

Cells $\left(5 \times 10^{5}\right)$ were collected after treatment with etoposide for $16 \mathrm{~h}$, resuspended in $450 \mu \mathrm{l}$ lysis buffer $(1 \%$ NP-40, $20 \mathrm{mM}$ EDTA, $50 \mathrm{mM}$ Tris-Cl, $\mathrm{pH}$ 7.5) on ice for 30 min. After centrifugation at $15,000 \mathrm{rpm}$ for $20 \mathrm{~min}$, the supernatant was collected and treated proteinase $\mathrm{K}$ (final concentration $0.5 \mu \mathrm{g} / \mathrm{ml}$ ) and $1 \%$ SDS for $2 \mathrm{~h}$ at $37^{\circ} \mathrm{C}$. DNA was obtained by phenol extraction following precipitation. The DNA was precipitated with $1 / 2$ volume of $10 \mathrm{M}$ ammonium acetate, 2.5 volume of isopropyl alcohol for 30 $\min$ at $-20^{\circ} \mathrm{C}$ and then centrifuged at $15,000 \mathrm{rpm}$ for 20 min. The pellet was dissolved in $15 \mu \mathrm{l}$ of TE buffer $(10 \mathrm{mM}$ Tris- $\mathrm{Cl}, \mathrm{pH}$ 8.0, $10 \mathrm{mM}$ EDTA) containing RNase A (final concentration $0.5 \mu \mathrm{g} / \mathrm{ml}$ ) and incubated for $2 \mathrm{~h}$ at $37^{\circ} \mathrm{C}$. After this digestion, the extract was fractionated by electrophoresis on $2 \%$ agarose at $40 \mathrm{~V}$ for $3 \mathrm{~h}$. DNA was visualized under UV light after staining with ethidium bromide (EtBr).

\section{RNA isolation and RT-PCR}

Total RNA from U937 cells was prepared using TRIzol (Invitrogen) according to the manufacturer's recommendation. The cDNA was synthesized from $2 \mu \mathrm{g}$ of total RNA with Moloney murine leukemia virus (MMLV) Reverse Transcriptase (Promega, Madison, WI) using a random hexamer at $37^{\circ} \mathrm{C}$ for $1 \mathrm{~h}$. The PCR primers for SHP gene amplification were: 5'-AGCTATGTGCACCTCATCGCACC- 
TGC-3 (sense), 5'-CAAGCAGGCTGGTCGGAATGGACTTG-3' (antisense); for $\beta$-actin gene amplification: 5'-GACTACCTCATGAAGATC-3' (sense), 5'-GATCCACATCTGCTGGAA-3' (antisense). The SHP cDNAs were amplified by PCR under the following conditions: 35 cycles of denaturation at $95^{\circ} \mathrm{C}$ for $20 \mathrm{~s}$, annealing at $55^{\circ} \mathrm{C}$ for $30 \mathrm{~s}$, and extension at $72^{\circ} \mathrm{C}$ for $30 \mathrm{~s}$ in a thermal cycler. The PCR products were examined by electrophoresis on $1.2 \%$ agarose gels.

\section{Western blot analysis}

U937 and HeLa cells were suspended in the lysis buffer (150 mM NaCl, 1\% NP-40, 1 mM EDTA, $50 \mathrm{mM}$ Tris, pH 7.5) containing protease inhibitors, and quickly sonicated on ice. Protein concentrations were measured using a commercial protein assay dye (Bio-Rad). The $30 \mu \mathrm{g}$ of cytoplasmic or nuclear protein was electrophoresed on $10 \%$ SDS-PAGE, or $30 \mu \mathrm{g}$ of soluble total cellular proteins was electrophoresed, and was electroblotted thereafter on PVDF membranes (Millipore). Binding of the primary antibody was detected using the ECL advance Western Blotting Detection kit (Amersham Biosciences).

\section{MTT assay}

For cell viability assay, cells were seeded in a 24-well tissue culture plate and incubated for $24 \mathrm{~h}$. Cells were trasfected with the indicated expression vectors and then etoposide was treated in the indicated concentration. After $24 \mathrm{~h}$, MTT solution $(0.5 \mathrm{mg} / \mathrm{ml})$ was added to each well. After incubation for $2 \mathrm{~h}$ at $37^{\circ} \mathrm{C}$, formazan crystals in viable cells were soluble in $200 \mu \mathrm{l}$ of DMSO. The soluble formazan product was spectrophotometrically quantified using an ELISA leader at $570 \mathrm{~nm}$.

\section{Statistical analysis}

The data is expressed as a mean \pm SD. The significant differences between the groups were determined using an unpaired Student's $t$-test. A $P$ value $<0.05$ was considered significant.

\section{Acknowledgements}

The authors wish to thank Dr. Michèle Sabbah and Dr. Heung Sik Choi for plasmids of pSUPER/p21 siRNA400 and $\mathrm{pGL} 2 \mathrm{~B} / \mathrm{hSHP}-\mathrm{Luc}(-2.2 \mathrm{~kb})$. This work was supported by the Bio-Scientific Research Grant funded by the Pusan National University (PNU, Bio-Scientific Research Grant) (PNU-2008-101-20080596000).

\section{References}

Andres V, Walsh K. Myogenin expression, cell cycle withdrawal, and phenotypic differentiation are temporally separable events that precede cell fusion upon myogenesis. J Cell Biol 1996;132:657-66

Angel P, Hattori K, Smeal T, Karin M. The jun proto-oncogene is positively autoregulated by its product, Jun/AP-1. Cell 1988;55:875-85

Asada M, Yamada T, Ichijo H, Delia D, Miyazono K, Fukumuro $\mathrm{K}$, Mizutani S. Apoptosis inhibitory activity of cytoplasmic p21(Cip1/WAF1) in monocytic differentiation. Embo J 1999; 18:1223-34

Baeuerle PA, Henkel T. Function and activation of NF-kappa $B$ in the immune system. Annu Rev Immunol 1994;12:141-79

Borgius LJ, Steffensen KR, Gustafsson JA, Treuter E. Glucocorticoid signaling is perturbed by the atypical orphan receptor and corepressor SHP. J Biol Chem 2002;277: 49761-6

Brendel C, Schoonjans K, Botrugno OA, Treuter E, Auwerx $J$. The small heterodimer partner interacts with the liver $X$ receptor alpha and represses its transcriptional activity. Mol Endocrinol 2002;16:2065-76

Casini T, Pelicci PG. A function of p21 during promyelocytic leukemia cell differentiation independent of CDK inhibition and cell cycle arrest. Oncogene 1999;18:3235-43

Choi YH, Park MJ, Kim KW, Lee HC, Choi YH, Cheong J. The orphan nuclear receptor SHP is involved in monocytic differentiation, and its expression is increased by c-Jun. $\mathrm{J}$ Leukoc Biol 2004;76:1082-8

Cory S. Regulation of lymphocyte survival by the bcl-2 gene family. Annu Rev Immunol 1995;13:513-43

Dignam JD, Lebovitz RM, Roeder RG. Accurate transcription initiation by RNA polymerase II in a soluble extract from isolated mammalian nuclei. Nucleic Acids Res 1983;11: 1475-89

Freytag SO. Enforced expression of the c-myc oncogene inhibits cell differentiation by precluding entry into a distinct predifferentiation state in G0/G1. Mol Cell Biol 1988;8: 1614-24

Fritah A, Saucier C, Mester J, Redeuilh G, Sabbah M. p21WAF1/CIP1 selectively controls the transcriptional activity of estrogen receptor alpha. Mol Cell Biol 2005;25: 2419-30

Gobinet J, Auzou G, Nicolas JC, Sultan C, Jalaguier S. Characterization of the interaction between androgen receptor and a new transcriptional inhibitor, SHP. Biochemistry 2001;40:15369-77

Gorospe M, Cirielli C, Wang X, Seth P, Capogrossi MC, Holbrook NJ. p21(Waf1/Cip1) protects against p53mediated apoptosis of human melanoma cells. Oncogene 1997;14:929-35

Halevy O, Novitch BG, Spicer DB, Skapek SX, Rhee J, Hannon GJ, Beach D, Lassar AB. Correlation of terminal cell cycle arrest of skeletal muscle with induction of p21 by MyoD. Science 1995;267:1018-21

Henkel GW, McKercher SR, Leenen PJ, Maki RA. Commitment to the monocytic lineage occurs in the absence of the transcription factor PU.1. Blood 1999;93:2849-58

Jang MK, Goo YH, Sohn YC, Kim YS, Lee SK, Kang H, Cheong J, Lee JW. Ca2+/calmodulin-dependent protein kinase IV stimulates nuclear factor-kappa B transactivation 
via phosphorylation of the p65 subunit. J Biol Chem 2001; 276:20005-10

Jiang H, Lin J, Su ZZ, Collart FR, Huberman E, Fisher PB. Induction of differentiation in human promyelocytic HL-60 leukemia cells activates p21, WAF1/CIP1, expression in the absence of $p 53$. Oncogene 1994;9:3397-406

Johansson L, Bavner A, Thomsen JS, Farnegardh M, Gustafsson JA, Treuter E. The orphan nuclear receptor SHP utilizes conserved LXXLL-related motifs for interactions with ligand-activated estrogen receptors. Mol Cell Biol 2000;20: 1124-33

Kelly LM, Englmeier U, Lafon I, Sieweke MH, Graf T. MafB is an inducer of monocytic differentiation. Embo J 2000;19: 1987-97

Kim DK, Cho ES, Lee SJ, Um HD. Constitutive hyperexpression of p21(WAF1) in human U266 myeloma cells blocks the lethal signaling induced by oxidative stress but not by Fas. Biochem Biophys Res Commun 2001a;289:34-8

Kim KJ, Kim HH, Kim JH, Choi YH, Kim YH, Cheong JH. Chemokine stromal cell-derived factor-1 induction by C/EBPbeta activation is associated with all-trans-retinoic acid-induced leukemic cell differentiation. J Leukoc Biol 2007;82:1332-9

Kim YS, Han CY, Kim SW, Kim JH, Lee SK, Jung DJ, Park SY, Kang H, Choi HS, Lee JW, Pak YK. The orphan nuclear receptor small heterodimer partner as a novel coregulator of nuclear factor-kappa $b$ in oxidized low density lipoproteintreated macrophage cell line RAW 264.7. J Biol Chem 2001b;276:33736-40

LaBaer J, Garrett MD, Stevenson LF, Slingerland JM, Sandhu C, Chou HS, Fattaey A, Harlow E. New functional activities for the p21 family of CDK inhibitors. Genes Dev 1997; $11: 847-62$

Larsson LG, Ivhed I, Gidlund M, Pettersson U, Vennstrom B, Nilsson K. Phorbol ester-induced terminal differentiation is inhibited in human U-937 monoblastic cells expressing a v-myc oncogene. Proc Natl Acad Sci U S A 1988;85:2638-42

Lee YK, Dell H, Dowhan DH, Hadzopoulou-Cladaras M, Moore DD. The orphan nuclear receptor SHP inhibits hepatocyte nuclear factor 4 and retinoid $X$ receptor transactivation: two mechanisms for repression. Mol Cell Biol 2000; 20:187-95

Lee YK, Moore DD. Dual mechanisms for repression of the monomeric orphan receptor liver receptor homologous protein-1 by the orphan small heterodimer partner. J Biol Chem 2002;277:2463-7

Lee YR, Yu HN, Noh EM, Youn HJ, Song EK, Han MK, Park CS, Kim BS, Park YS, Park BK, Lee SH, Kim JS. TNF-alpha upregulates PTEN via NF-kappaB signaling pathways in human leukemic cells. Exp Mol Med 2007;39:121-7

Lubbert M, Herrmann F, Koeffler HP. Expression and regulation of myeloid-specific genes in normal and leukemic myeloid cells. Blood 1991;77:909-24

Migliaccio E, Giorgio M, Mele S, Pelicci G, Reboldi P, Pandolfi PP, Lanfrancone L, Pelicci PG. The p66shc adaptor protein controls oxidative stress response and life span in mammals. Nature 1999;402:309-13

Nerlov C, Graf T. PU.1 induces myeloid lineage commitment in multipotent hematopoietic progenitors. Genes Dev 1998; $12: 2403-12$

Nguyen HQ, Hoffman-Liebermann B, Liebermann DA. The zinc finger transcription factor Egr-1 is essential for and restricts differentiation along the macrophage lineage. Cell 1993;72:197-209

Oberg F, Botling J, Nilsson K. Macrophages and the cytokine network. Transplant Proc 1993;25:2044-7

Park MJ, Kong HJ, Kim HY, Kim HH, Kim JH, Cheong JH. Transcriptional repression of the gluconeogenic gene PEPCK by the orphan nuclear receptor SHP through inhibitory interaction with C/EBPalpha. Biochem J 2007;402: 567-74

Pennington KN, Taylor JA, Bren GD, Paya CV. IkappaB kinase-dependent chronic activation of NF-kappaB is necessary for $\mathrm{p} 21$ (WAF1/Cip1) inhibition of differentiationinduced apoptosis of monocytes. Mol Cell Biol 2001;21: 1930-41

Polyak K, Waldman T, He TC, Kinzler KW, Vogelstein B. Genetic determinants of $\mathrm{p} 53$-induced apoptosis and growth arrest. Genes Dev 1996;10:1945-52

Sanyal S, Kim JY, Kim HJ, Takeda J, Lee YK, Moore DD, Choi HS. Differential regulation of the orphan nuclear receptor small heterodimer partner (SHP) gene promoter by orphan nuclear receptor ERR isoforms. J Biol Chem 2002;277: $1739-48$

Scott EW, Simon MC, Anastasi J, Singh H. Requirement of transcription factor PU.1 in the development of multiple hematopoietic lineages. Science 1994;265:1573-7

Seol W, Choi HS, Moore DD. An orphan nuclear hormone receptor that lacks a DNA binding domain and heterodimerizes with other receptors. Science 1996;272:1336-9

Sherman ML, Stone RM, Datta R, Bernstein SH, Kufe DW. Transcriptional and post-transcriptional regulation of c-jun expression during monocytic differentiation of human myeloid leukemic cells. J Biol Chem 1990;265:3320-3

Sherr CJ, Roberts JM. Inhibitors of mammalian G1 cyclin-dependent kinases. Genes Dev 1995;9:1149-63

Steinman RA, Hoffman B, Iro A, Guillouf C, Liebermann DA, el-Houseini ME. Induction of p21 (WAF-1/CIP1) during differentiation. Oncogene 1994;9:3389-96

Szabo E, Preis LH, Brown PH, Birrer MJ. The role of jun and fos gene family members in 12-O-tetradecanoylphorbol13-acetate induced hemopoietic differentiation. Cell Growth Differ 1991;2:475-82

Tanaka H, Yamashita T, Asada M, Mizutani S, Yoshikawa H, Tohyama M. Cytoplasmic p21(Cip1/WAF1) regulates neurite remodeling by inhibiting Rho-kinase activity. J Cell Biol 2002;158:321-9

Wang Z, Su ZZ, Fisher PB, Wang S, VanTuyle G, Grant S. Evidence of a functional role for the cyclin-dependent kinase 
inhibitor $\mathrm{p} 21$ (WAF1/CIP1/MDA6) in the reciprocal regulation of PKC activator-induced apoptosis and differentation in human myelomonocytic leukemia cells. Exp Cell Res 1998; 244:105-16
Yeo MG, Yoo YG, Choi HS, Pak YK, Lee MO. Negative cross-talk between Nur77 and small heterodimer partner and its role in apoptotic cell death of hepatoma cells. Mol Endocrinol 2005;19:950-63 